\title{
Image Processing Mobile Application For Banana Ripeness Evaluation
}

\author{
Kuryati Kipli \\ Faculty of Engineering \\ Universiti Malaysia Sarawak, \\ Kota Samarahan, Sarawak, Malaysia \\ Email: kkuryati@unimas.my \\ Hushairi Zen \\ Faculty of Engineering \\ Universiti Malaysia Sarawak, \\ Kota Samarahan, Sarawak, Malaysia \\ Marini Sawawi \\ Faculty of Engineering \\ Universiti Malaysia Sarawak, \\ Kota Samarahan, Sarawak, Malaysia
}

\author{
Mirza Syazwana Mohamad Noor \\ Faculty of Engineering \\ Universiti Malaysia Sarawak, \\ Kota Samarahan, Sarawak, Malaysia
}

\author{
Norhuzaimin Julai \\ Faculty of Engineering \\ Universiti Malaysia Sarawak, \\ Kota Samarahan, Sarawak, Malaysia \\ Nazreen Junaidi \\ Faculty of Engineering \\ Universiti Malaysia Sarawak, \\ Kota Samarahan, Sarawak, Malaysia
}

\author{
Muhammad Izzat Shafiq Mohd Razali \\ Faculty of Computer Science and \\ Information Technology \\ Universiti Malaysia Sarawak, \\ Kota Samarahan, Sarawak, Malaysia \\ Kho Lee Chin \\ Faculty of Engineering \\ Universiti Malaysia Sarawak, \\ Kota Samarahan, Sarawak, Malaysia \\ Sharifah Masniah Wan Masra \\ Faculty of Engineering \\ Universiti Malaysia Sarawak, \\ Kota Samarahan, Sarawak, Malaysia
}

\begin{abstract}
Mobile application has been identified as the best platform for the expert system tool to reach as many users as possible. The main contribution of this paper is the development of an expert system tool for evaluating the ripeness of banana fruit. Utilizing Google Cloud Platform, the application sends the sample of banana image through Google Cloud Vision Application Programming Interface to get attribute readings from the sample image. The result of the analysis is compared with application's database of attributes datasets to determine the ripeness of the banana sample image. In this work, the ripeness of the banana is classified into three different class of maturity; unripe, ripe and overripe systematically based on their key attributes value. This work also involved the process of collecting samples of banana with different level of ripeness, application development and evaluation to improve the accuracy of the developed applications classification results using image processing and data mining techniques.
\end{abstract}

Keywords - Mobile Application, Image Processing, Fruit, Ripeness, Data Mining, Rule Based Classification

\section{INTRODUCTION}

$\mathrm{M}$ obile application offers huge practicality for users as mobile devices are already equipped with camera, compared with desktop software that requires additional hardware for image input. Other than that, mobile devices such as smartphone had already becoming an important aspect in human life with the number of smartphone user forecasted to grow from 2.32 billion to around 2.87 billion in 2020 [1]. Over 36 percent of the world's population is forecasted to use a smartphone by 2018 [1]. Two most popular mobile application platforms are Google's Android and Apple's iOS.

According to Malaysia's Department of Statistics, banana is the fourth most consumed fruit produce in Malaysia with per capita consumption of $9.5 \mathrm{~kg}$ per year [2] . Consumption of banana surpasses other fruits such as watermelon, rambutan and mango. Banana is consumed daily in Malaysia as the fruit serve as a reliable source of energy. In this paper, banana is chosen to be evaluated due to its huge availability in the market and has a high demand among the consumers [3]. Imported species of banana found in the large supermarkets are commonly genetically modified organisms which are cultivated to last a longer time than the normal local bananas. The novelty of this work is at evaluating local species of banana using image processing techniques.

Bananas are commonly evaluated by its skin colour. However, consumers may want to keep the bananas for consumption at later time (e.g. 2 weeks), thus they would choose to buy immature bananas instead of ripe bananas. Consumers also may have difficulty to know if the banana is at its best-for-consumption period. Thus this paper introduces an accurate solution to determine the maturity of bananas accordingly. In agricultural industries, there are methods and tools for quality control in large scale production. However, for small scale local farmers, such technology is not easily accessible and available. Experienced farmers may already have the skills required to determine the fruit maturity by observations. Beginners or new local banana farmers would benefit from this work, which serves as an expert system tool to help them determine the maturity of produce accurately.

The main contributions of this paper include: 1) to develop a classification model for image processing of banana ripeness, 2) to integrate classification model into a mobile application platform, 3) design and build mobile application (as an expert system tool) for evaluation of banana fruit ripeness and 4) to utilize Google Vision API in Google Cloud Platform in processing image attributes from the mobile application. This research also involves the process of collecting samples of banana with different level of ripeness, building classification 